\title{
Consumo digital como performance sociotécnica: Análise dos usos da plataforma de streaming de games Twitch
}

\section{Digital consuptiom as sociotechnical performance: Analysis of the uses of the game streaming platform Twitch}

\author{
Sandra Montardo ${ }^{1}$ \\ Suely Fragoso ${ }^{2}$ \\ Mariana Amaro 3 \\ Samyr Paz
}

Resumo: Este artigo tem como objetivo discutir as interrelações entre performance, consumo digital e condicionantes de interface na plataforma de streaming de games Twitch. Considerações teóricas sobre os três aspectos são comparadas às respostas obtidas através de um questionário online, respondido por 177 usuários brasileiros do Twitch. Os resultados indicam que, a despeito da importância do aspecto de mídia social para o Twitch, as interfaces não facilitam a interação social. As relações hierárquicas implícitas entre os streamers e o público não resultam apenas da expertise dos primeiros. O consumo digital demanda que eles demonstrem outras habilidades, como a performance "entreter". O próprio Twitch coloca desafios adicionais para os streamers e viewers, de ordem técnica e cognitiva, mas a base de usuários parece ser auto-motivada o suficiente para superar esses obstáculos do sistema.

Palavras-Chave: Consumo digital; Performance; Twitch; Affordance; Interface;

1 Universidade Feevale. Rio Grande do Sul, RS, Brasil. E-mail: sandramontardo@feevale.br

2 Universidade Federal do Rio Grande do Sul. Rio Grande do Sul, RS, Brasil. E-mail: suelyfragoso@ufrgs.br

3 Universidade Federal do Rio Grande do Sul. Rio Grande do Sul, RS, Brasil. E-mail: mari.amaroc@gmail.com

4 Universidade Feevale. Rio Grande do Sul, RS, Brasil. E-mail: samyrpaz@gmail.com 
Abstract: This article discusses the interrelations between performance, digital consumption and interface features on the game streaming platform Twitch. Theoretical considerations on the three subjects are compared to the responses of 177 Brazilian Twitch users to an online questionnaire. Results indicate that, despite their importance for Twitch as social media, interfaces do not facilitate social interactions. The implied hierarchical relations between streamers and viewers is not only based on the expertise of the former group. Digital consumption demands that they demonstrate other abilities, such as the "entertain" performance. Twitch itself places additional technical and cognitive challenges on streamers and viewers, but its user base appears to be self-motivated enough to overcome those system obstacles.

Keywords: Digital consumption; Performance; Twitch; Interface; Affordance; 


\section{Introdução 5}

O streaming de games é um fenômeno recente, mas já envolve milhares de pessoas que transmitem e assistem jogos por plataformas específicas, entre as quais destacaremos o Twitch. Com mais de 100 milhões de espectadores mensais e 1,7 milhão de streamers únicos (Twitch, 2016), além de contar com o quarto maior tráfego de internet dos Estados Unidos (The Wall Street Journal, 2015), o Twitch é um fenômeno social, midiático e cultural merecedor de atenção. No entanto, a bibliografia sobre o Twitch ainda é bastante restrita em número e está concentrada em fenômenos específicos, como a experiência social Twitch Plays Pokémon $^{6}$ (AMARO; FREITAS, 2016; GARROCHO; JOSEPHSON, 2014; LEITE; TESSAROLO, 2014; PAZ, 2015). Entretanto, não encontramos trabalhos brasileiros com o foco ou a abordagem que desenvolvemos neste artigo.

A partir da percepção de analisar as interações em termos dos conceitos de performance (SCHECHNER, 2003; EHRENBERG, 2010), bem como de consumo digital (MONTARDO, 2016), consideramos relevante investigar as condições da performance em sites de rede social (MONTARDO; SILVA, 2015a, 2015b, 2015c) na plataforma de streaming de games Twitch, cuja temática são os jogos digitais. Em relação a esta plataforma - na qual usuários (ou streamers) têm a função de exibirem-se jogando, ou de audiência desses jogadores - pergunta-se: como os usuários identificam performance no Twitch? A quem e a quê atribuem essa percepção? De que forma o tipo de jogo eletrônico ou perfil de streamer influenciam nesse entendimento? E, finalmente, como a própria plataforma interfere nessa identificação? Este artigo tem por objetivo discutir as performances realizadas no Twitch a partir do ponto de

5 Trabalho originalmente apresentado ao Grupo de Trabalho Comunicação e Cibercultura do XXV Encontro Anual da Compós, na Universidade Federal de Goiás, Goiânia, realizado entre 7 a 10 de junho de 2016.

6 Trata-se de um experimento cujo criador permanece anônimo, em que comandos do IRC (Internet Relay Chat) foram utilizados no chat do Twitch, possibilitando que a audiência controlasse o jogo Pokémon Red que estava sendo transmitido. 
vista dos usuários da plataforma. Para tanto, lançamos um questionário online que recebeu 177 respostas válidas, de usuários brasileiros.

Antes da apresentação e análise dos resultados obtidos, esclareceremos nas próximas seções as ideias que suportam teoricamente o conceito de consumo como performance e as abordagens sociotécnicas das affordances em interfaces de sites de redes sociais, bem como as problematizações inerentes a essas articulações teóricas.

\section{Consumo digital como performance em sites de redes sociais}

Montardo (2016) articulou os conceitos de consumo, performance e site de redes sociais e propôs conceito de consumo digital a partir de uma interpretação de consumo via teoria de prática. Esse movimento representou avanços em relação a trabalhos como o de Warde (2005), para quem o consumo se dá dentro e em função de práticas, de modo que estas requerem o consumo de determinados produtos e serviços para serem possíveis, bem como determinados conhecimentos por parte de quem as conduz. Para o autor, possíveis gratificações seriam decorrentes das práticas que inspiram o consumo de algo, e não o contrário; de modo que não é o consumo que oferece satisfação, mas a performance inerente a práticas que, por sua vez, requerem posse ou acesso de determinados bens e serviços para se efetivarem. Transpondo essa concepção para a comunicação digital, entende-se que o consumo digital é o que torna possível a prática da socialização online. O consumo digital é aquele que consiste no acesso, na produção, na disponibilização e no compartilhamento de quaisquer tipos de conteúdo digital (texto verbal, visual, animações, imagens, vídeos, etc.), envolvendo ou não a alocação de recursos financeiros, caso se possa identificar os atores em interação e, consequentemente, suas performances em determinados espaços (MONTARDO, 2016).

Em relação à performance, entende-se com Ehrenberg (2010) que o contexto atual implica peculiaridades importantes e que precisam 
ser levadas em conta. Entre elas, destaca- se a constituição da identidade, que passa de herdada, na Antiguidade, para uma construção que consiste em um projeto voltado para o futuro e dependente de uma performance individual. Por sua vez, Schechner (2003) compreende que performance são comportamentos restaurados, espécie de vários "retalhos" aprendidos que são acionados no fluxo do tempo. Toda e qualquer ação pode ser analisada como performance, desde que observada em determinado contexto cultural, afirma o autor. Neste trabalho, o contexto cultural é o streaming de games, onde a performance será analisada pelas seguintes categorias: entreter; fazer algo belo; marcar ou mudar a identidade; fazer ou estimular uma comunidade; curar; ensinar, persuadir ou convencer; lidar com o sagrado e com o demoníaco. Schechner (2003) explica que essas classificações nem sempre são unitárias, já que é possível identificar mais de um tipo de performance em determinada ação observada.

Entre os artigos nos quais foi identificado o consumo digital em diferentes sites de redes sociais nesses termos, destacam-se três cujas as relações apoiam esta problematização (MONTARDO; SILVA, 2015a, 2015b, 2015c). Uma dessas publicações (MONTARDO; SILVA, 2015a) lançou um conceito que interessa ao presente trabalho, que é o de site de rede social temático, com o qual são designados ambientes digitais projetados para sustentar a socialização online em torno de objetos de consumo específicos. Frente a isso, percebeu-se a importância da análise do capital social alocado nas interações em sites de redes sociais temáticos, com o cuidado de considerar os fatores que influenciam a motivação principal de participar desses ambientes.

Montardo e Silva (2015b) buscaram no conceito de capital social um apoio para sistematizar as relações sociais. Recuero (2009) ressalta que o conceito viabiliza análises das relações entre os atores de uma rede e as consequências dessas ações na estrutura das redes sociais, considerando não apenas as conexões de uma rede, mas também o conteúdo das trocas sociais. A autora traz a categorização de Bertolini e Bravo (2001), que propuseram a compreensão de capital social em dois níveis, cada 
um deles com subtipos, sendo os do primeiro nível relacional, normativo e cognitivo e os do segundo nível, confiança no ambiente social e institucional. Uma vez identificado um dos primeiros tipos na análise de relação social, pode-se analisá-lo em termos de configuração do segundo tipo, conforme as apropriações feitas pelos atores em sites de redes sociais (MONTARDO; SILVA, 2015b).

Em um terceiro artigo, Montardo e Silva (2015c) verificaram uma inversão em relação às observações anteriores de Recuero (2009) quanto à alocação de capital social em sites de redes sociais. Os resultados obtidos por elas indicam que os tipos de capital social de primeiro nível (cognitivo, relacional e normativo) provêm da ação entre os usuários do site (relações emergentes), enquanto que os de segundo nível (confiança no ambiente social e institucional) são fortemente influenciados pelo sistema que suporta as interações. Ou seja, a confiança no ambiente social é garantida pelo fato de se tratar de um site projetado para se restringir a um determinado tema. Esse resultado foi obtido pelo fato de a análise ter sido centrada na análise de sites de redes sociais temáticos, os quais são projetados para sustentar a socialização em torno de um tema único. No entanto, a questão de o capital social de primeiro nível emergir da relação entre os usuários, e o de segundo nível ser mais influenciado pelo sistema, pode ser extensível, também, a outras situações sociais mediadas em torno de temas específicos, como a criação de páginas e grupos no Facebook, ou nas antigas comunidades do Orkut, ou, ainda, em certos tipos de jogos online (FRAGOSO, 2006, 2008, 2015).

\section{Abordagens sociotécnicas das affordances em interfaces de sites de redes sociais}

Características de caráter aparentemente mais técnico do que social dos sistemas de rede social costumam ser consideradas temas para outras áreas de conhecimento, e não da Comunicação. No entanto, como defende Fragoso (2014), os aspectos técnicos e sociais de um artefato são inseparáveis. Para a autora, não é sequer suficiente estudá-los em 
conjunto: é preciso compreendê-los como uma única e mesma condição. Para demarcar nossa opção por essa mesma abordagem, daremos preferência à expressão "sociotécnico" em lugar de social, ou técnico. Tomaremos o cuidado, entretanto, para evitar as distorções que já se tornaram comuns devido ao uso excessivo da expressão. Afinal, Fragoso (2014) também alerta que trabalhos que procuram identificar e discutir relações entre formas de uso e interação e características do design de artefatos digitais correm sério risco de degenerar para o determinismo, seja ele técnico ou sociológico. Isso decorre da própria forma de colocar a questão, que, já de saída, diferencia o técnico e o social. No entanto, como coloca Castells (1998, p. 25), "a sociedade não pode ser entendida ou representada sem suas ferramentas tecnológicas" e, nesse sentido, “a tecnologia é a sociedade".

Exatamente porque o social e o técnico não são duas entidades é que a combinação ou justaposição de tecnologia e sociedade não dá conta da complexidade do caráter sociotécnico dos artefatos. Neste trabalho, a expressão "sociotécnico" não será utilizada para designar as relações entre um sistema social e um sistema técnico, mas, em convergência com Molina (1998) e Klein (2014), para designar aspectos de um único sistema. Essa compreensão torna mais segura a adoção de uma estrutura de análise baseada no conceito de "affordance sociotécnica", proposto por Fragoso, Rebs e Barth (2012) que estudaram a relação entre as affordances das interfaces de sites de redes sociais e as práticas que ocorrem nesses sites, tendo como exemplos plataformas de microblogging. No estudo, as autoras destacaram a importância de recuperar o conceito original de affordance em Gibson (1977), para quem as affordances, dizem respeito ao comportamento de animais específicos (neste trabalho, os humanos). As affordances existem independente da capacidade que o animal tem de percebê-las. Porém, como enfatizou Gibson (1977) affordances não são nem objetivas, nem subjetivas, pois dizem respeito ao mesmo tempo ao ambiente e ao observador. Por esse motivo, Fragoso, Rebs e Barth (2012) discordam de Norman (2006) e afirmam que as características reais de uma interface são mais importantes do que aquelas 
que os usuários demonstram perceber em um dado momento. Para elas, os elementos de uma interface de site de rede social ou software não são realmente affordances, mas induzem à percepção de certas affordances, enquanto escondem outras. As autoras adotam a posição de Hartson (2003), para quem a distinção entre affordances reais e percebidas, popularizada a partir de Norman (2006), deve ser recolocada em termos de affordances físicas e cognitivas. Esse movimento permite ir além da concepção de affordances como representações visuais ou textuais na tela. Para Hartson, affordance cognitiva é "um elemento de design que ajuda, apoia, suporta, facilita ou permite pensar ou saber sobre algo" (2003, p. 319). O papel do designer de interfaces é escolher e distribuir affordances cognitivas, enfatizando certas affordances físicas (possibilidades reais oferecidas pelo sistema) e tornando outras menos visíveis. Essa visão de design de interfaces ultrapassa a ideia de que cabe ao designer saber o que o usuário precisa e informá-lo sobre os melhores modos de atingir seus objetivos, permitindo ou negando interações.

Vale destacar, ainda, que, em seu retorno a Gibson (1977), Fragoso, Rebs e Barth (2012) convergem com a noção de artefato sociotécnico que apresentamos anteriormente. Tendo baseado seu conceito de affordance em estudos do comportamento animal, Gibson o definiu como relações recíprocas entre o ambiente e o animal. Já na condição humana, isso corresponde ao reconhecimento da associação entre os aspectos tecnológicos e socioculturais para a definição das significações e dos usos da tecnologia. Para as autoras, o que os usuários fazem não é apenas aproveitar as affordances das interfaces, pois eles desempenham um papel ativo no estabelecimento daquelas affordances. Uma vez que as affordances são mais relativas à ação e menos à percepção (GAVER, 1991), elas devem ser estudadas como tal. Isso significa que não é razoável analisar um artefato digital (site, aplicativo, game) isolando os elementos de sua interface dos modos como eles são compreendidos e dos usos que são dados a eles, ou vice-versa. 
No contexto dos sites de rede social e outras formas da "face aplicativo" da web ${ }^{7}$, toda análise precisa levar em conta os aspectos técnicos e os sociais de forma integrada. Para isso é preciso empreender uma diferenciação entre as interações com o artefato tecnológico (estritamente, interações com o dispositivo sociocultural que se materializa no artefato) e as interações com outros indivíduos que também se apropriam daquele artefato. Especial cuidado é necessário para não retornar ao descolamento das faces técnica e social do artefato e da interação.

\section{Twitch e Audiência}

O Twitch é um site/plataforma de vídeos ao vivo dedicado à transmissão de partidas de jogos eletrônicos para o nicho gamer. O que se iniciou como um nicho num site de transmissões online domésticas rapidamente ultrapassou o público de outros segmentos e se tornou um gigante de audiência, sendo comprado pela Amazon em 2011.

Assim, o Twitch se destaca dos concorrentes pela popularidade, um certo caráter de pioneirismo e pela capacidade de movimentar negócios na indústria de jogos e tecnologia. O slogan "Social Video for Gamers" destaca a proposta do Twitch, que consiste basicamente no streaming. A palavra pode ser traduzida como transmissão ${ }^{8}$ e é basicamente essa a função do Twitch: permitir que os usuários transmitam ao vivo suas sessões de jogos. A transmissão pode ser realizada por computadores ou videogames com conexão à internet ${ }^{9}$. Do outro lado, os espectadores podem assistir através de diversos dispositivos conectados à internet. Não é necessário ser um usuário cadastrado para assistir as transmissões, porém

7 Por "face aplicativo" estamos nos referindo a funcionalidades que tiram partido da infraestrutura da web para realizar ações e usos mais próximos do universo dos softwares do que da disponibilização e acesso à informação. A colocação é inspirada em Garrett (2011).

8 Daremos preferência ao termo inglês streaming de games por se tratar da forma utilizada pela comunidade brasileira. Chamaremos aqueles que transmitem sessões de jogos de streamers ou broadcasters, e de espectadores, audiência ou viewers aqueles que assistem.

9 Evitaremos detalhamentos técnicos que não sejam necessários para os pontos de que trataremos no artigo. No entanto, a plataforma mais utilizada pelos streamers é o PC, que exige a instalação de softwares de terceiros para a captação de vídeo. O próprio Twitch disponibiliza alguns links para download destes softwares. 
para usufruir de todas ferramentas proporcionadas pelo Twitch, o registro se faz necessário.

Cada streamer adota dinâmicas próprias para seus canais, na tentativa de entreter e manter a audiência interessada. Cada escolha, desde o jogo a ser transmitido até formas de interação com a audiência, refletem no tipo de audiência que o canal vai atrair. Os streamers são tanto apreciadores de videogame quanto jogadores profissionais, que participam de campeonatos, ou gamers que já conquistaram fama pela sua dedicação ao streaming. Entre os canais do Twitch, existem os especializados em transmitir campeonatos e competições de videogames (e-sports), e outros, sobre técnicas criativas para desenvolvimento de jogos, por exemplo. Nota-se que o Twitch está ligado a uma vasta gama de interesses da indústria de games.

Estamos chamando de audiência aqueles usuários do Twitch que assistem as partidas e interagem com o jogo somente por meio do chat (escrito). A eles não é possível acompanhar os jogos por meio do player de vídeo embutido na interface do canal do streamer, o que implica que, resguardadas as exceções (como visto em Twitch Plays Pokémon), não podem estabelecer controle direto sobre o jogo. Eles formam a comunidade que capitaliza o site, não só ao pagar em dinheiro para ter acesso a algumas possibilidades restritas, mas ao fornecer ao Twitch o capital social que lhe permite firmar parcerias com anunciantes e produtoras de jogos.

A experiência do streamer é muito diferente da experiência da audiência. Em primeiro lugar, porque as possibilidades sociotécnicas que o Twitch oferece aos broadcasters são diferentes daquelas disponíveis para as audiências. Os broadcasters mais populares tiram partido desse desequilíbrio assumindo práticas de gerenciamento da audiência (criando promoções e ofertas de itens especiais para os seguidores de seus canais), via, por exemplo, o uso de vinhetas.

A característica que mais distancia as performances dos streamers e da audiência é o fato de que, antes de ocupar o papel de emissor, o streamer é necessariamente um jogador, ou seja, um gamer. Mesmo quando 
não há streaming, o gamer é uma das partes ativas da construção da mensagem, do significado e do próprio jogo digital (SOMMERSETH, 2007). Na verdade, o papel de jogador só existe quando o sujeito está, de fato, envolvido no processo cognitivo e corpóreo de jogar (HUIZINGA, 2010). Ao sair do jogo, a sua caracterização - e função - como jogador acaba.

Portanto, mesmo que a participação de um espectador do Twitch por meio do chat interfira nas ações do streamer, isto não iguala a sua agência à do broadcaster. A audiência detém várias possibilidades de influência sobre o jogador, porém só o streamer tem o controle do avatar no "mundo de jogo" e, portanto, ele é o único que pode interagir com os elementos que compõem aquele mundo. Desse modo, as ações do streamer têm consequências diretas no espaço de jogo, e os espectadores se reúnem em torno dessas ações, na maior parte das vezes, com o intuito de apreciação.

Tomando de empréstimo a ideia de círculo mágico (HUIZINGA, 2010), pode-se dizer que, ao se engajar com o jogo, o jogador aceita participar de uma outra realidade, na qual lhe é permitido o exercício da agência (FALCÃO, 2010). O tipo de interação proporcionada pelo jogo digital modifica a experiência e o potencial da mensagem. A possibilidade de controlar os acontecimentos implica em responsabilidade pelo que ocorre (ou não ocorre) no jogo. Por isso, mesmo em ambientes como o Twitch, onde quem assiste a partida pode interagir diretamente com o jogador e esse responda, inclusive, potencialmente, alterando algo em seu modo de jogo, o ato de jogar continua sendo fundamentalmente diferente de assistir a uma partida e comentá-la. Basta lembrar que se o jogador optar por não agir, não haverá sessão, nem mesmo jogo. Já os espectadores podem optar por só assistir, não interagindo no chat, ou mesmo por não assistir, sem que isso influencie a continuidade da partida.

Evidentemente, essas diferenças nas interações dos streamers e da audiência demandam diferenças nas interfaces utilizadas pelos dois grupos. Enquanto o espectador fica limitado à interface do Twitch, o 
streamer utiliza uma série de interfaces diferentes durante o streaming, muitas das quais não estão acessíveis para o viewer. Além do Twitch, os streamers precisam utilizar outros programas, específicos para a captura e transmissão da imagem e do áudio do jogo; de sua imagem na webcam; e de seu áudio, pelo microfone.

No Quadro 1 podem ser vistos alguns exemplos das interfaces que o streamer deve navegar para realizar a transmissão. Entre todas as interfaces e telas, o broadcaster deve concentrar a maior parte da sua atenção à interface do jogo, já que a intenção é tornar público seu desempenho durante uma partida, em tempo real.

QUADRO 1. Comparativo entre funcionalidades disponíveis para o espectador e o jogador streamer.

\begin{tabular}{|c|c|c|c|c|c|c|c|}
\hline & $\begin{array}{c}\text { Interface } \\
\text { da } \\
\text { página } \\
\text { da } \\
\text { partida } \\
\text { no } \\
\text { Twitch }\end{array}$ & $\begin{array}{c}\text { Interface } \\
\text { da } \\
\text { dashboard }\end{array}$ & $\begin{array}{c}\text { Interface } \\
\text { do } \\
\text { programa } \\
\text { de } \\
\text { transmissão }\end{array}$ & Jogo & $\begin{array}{c}\text { Chat } \\
\text { Escrito }\end{array}$ & $\begin{array}{c}\text { Microfone } \\
\text { (para } \\
\text { comunicação) }\end{array}$ & $\begin{array}{c}\text { Webcam } \\
\text { (para } \\
\text { comunicação) }\end{array}$ \\
\hline Espectador & Utiliza & - & - & Assiste & $\begin{array}{c}\text { Lê e escreve } \\
\text { Ossiste }\end{array}$ & Ouve & Le escreve \\
\hline $\begin{array}{c}\text { Jogador } \\
\text { Streamer }\end{array}$ & - & Utiliza & Utiliza & Joga & $\begin{array}{c}\text { Lê e eng-ins, } \\
\text { dashboard ou } \\
\text { outra tela) }\end{array}$ & Fala & É filmado \\
\hline
\end{tabular}

Fonte: Os autores.

Cabe aqui também salientar que o jogador streamer tem uma performance diferente da que assumiria em uma situação privada de jogo. A existência, ou mesmo o desejo de uma audiência, evoca, direta e indiretamente, condições anormais de atenção, alterando o gameplay. $\mathrm{O}$ fato de que o streamer joga para exibir sua habilidade, bem como a disponibilização da própria imagem através de uma webcam, já seriam suficientes para modificar a experiência de jogo em relação a uma partida tradicional. Contudo, outra modificação de experiência decorre da necessidade de dividir a atenção entre o jogo e as mensagens enviadas pelos viewers, interagindo com ambos simultaneamente, assim como monitorar os sinais da transmissão em uma série de interfaces diferentes daquela do game. 
Finalmente, assinalamos que, como qualquer viewer pode perceber, os streamers já compreenderam que a maestria como jogadores não é o único modo de atrair a audiência para que acompanhe seu canal. Isso tem levado os streamers a adotarem outras estratégias de atração, inexistentes em situações sem caráter público. Nesse movimento, tornam-se "animadores" midiáticos de um tipo mais habitual, pois, se a experiência do jogador não depende de espetacularização, a audiência parece ser atraída pelo espetáculo.

\section{Método e resultados obtidos}

Nas seções anteriores, apresentamos a bibliografia, da qual emergiram os vetores teóricos de análise (consumo digital, performance, affordances cognitivas e físicas); e a pesquisa documental sobre o Twitch. Para completar nosso quadro de análise, descreveremos a seguir o questionário aplicado aos usuários do Twitch e as respostas obtidas.

A finalidade do questionário que disponibilizamos online era identificar a percepção da audiência sobre as performances possíveis no Twitch. O instrumento ficou disponível entre 2/12/2015 e 21/01/2016 e foi respondido por 177 usuários. Era composto de 40 questões, 35 fechadas e 5 abertas, divididas em partes que contemplavam:

A. o perfil dos respondentes, plataforma e seus usos;

B. características preferidas em relação aos streamers;

C. a relação entre usuários.

Os pontos de partida da divulgação foram os perfis pessoais dos pesquisadores no Facebook e Twitter. Além disso, também houve divulgação em grupos e comunidades dedicadas a games e ao streaming, como o grupo Twitch Brasil no Facebook e a rede de streamers EGL Network.

Encerrado o processo, podemos dizer que o perfil dos respondentes era jovem (entre 18 e 25 anos (58\%) ou entre 26 e 35 anos (29\%) e a grande maioria $(88 \%)$ era do sexo masculino. Quase a metade está cursando graduação (41\%), enquanto $23 \%$ têm Ensino Médio completo e outros $16 \%$ têm curso superior completo. Suas residências se dividem entre o sul (38\%) e sudeste (37\%) do Brasil. Quase todos (96\%) jogam 
videogames com frequência, principalmente no PC (95\%). Os dispositivos móveis (32\%), Playstation 3 (23\%) e Xbox 360 (17\%) aparecem em sequência como as plataformas escolhidas para jogar. Mais de um terço (34\%) informou ser usuário do Twitch desde 2013, 18\% desde 2014 e outros $18 \%$ desde 2012. Os respondentes também informaram que acessam o Twitch todos os dias (61\%) ou mais de uma vez por semana (25\%), durante duas horas ou três horas (54\%), quatro horas ou mais $(25 \%)$ ou até uma hora (21\%). Durante esse tempo, a maioria acompanha três ou mais canais (67\%), enquanto $30 \%$ assistem duas ou três transmissões e $3 \%$ preferem apenas um canal ${ }^{10}$.

Quando questionados sobre qual atividade passam mais tempo exercendo no Twitch em uma ordem crescente, obteve-se o resultado apresentado na figura 1 .

FIGURA 1. Gráfico das atividades que os respondentes mais passam tempo realizando no Twitch ${ }^{11}$

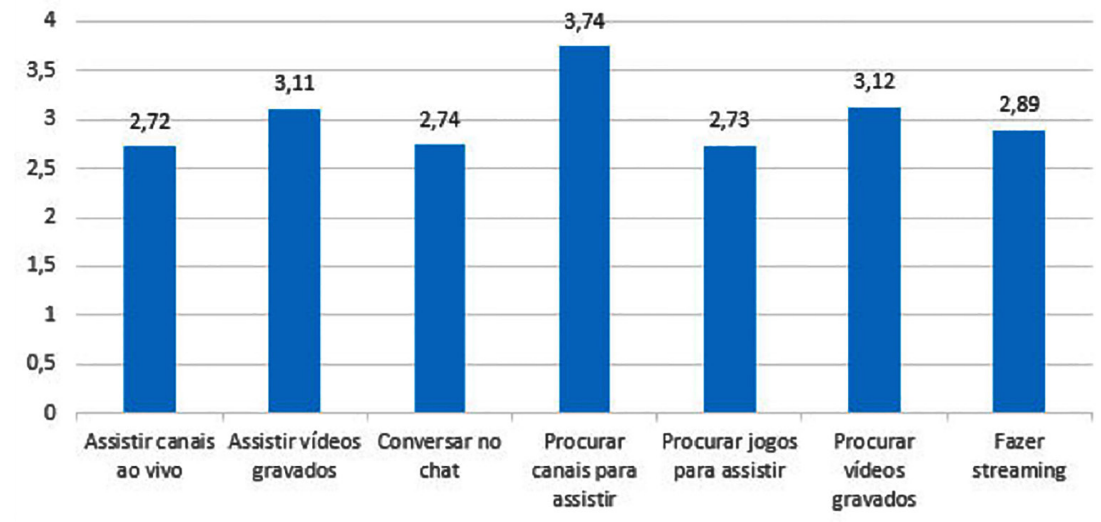

Fonte: Os autores.

10 É importante destacar que nosso estudo não teve pretensões estatísticas, o que demandaria uma amostra de milhares de respondentes e cuidadosa distribuição demográfica. Embora alguns parâmetros sejam semelhantes aos divulgados pelo próprio Twitch, o perfil que descrevemos tem a intenção de retratar os respondentes.

11 Para interpretar os dados, é necessário levar em conta que o valor mais próximo de 1 representa o que os respondentes passam mais tempo fazendo. 
FIGURA 2. Gráfico dos níveis de dificuldade das ações no Twitch

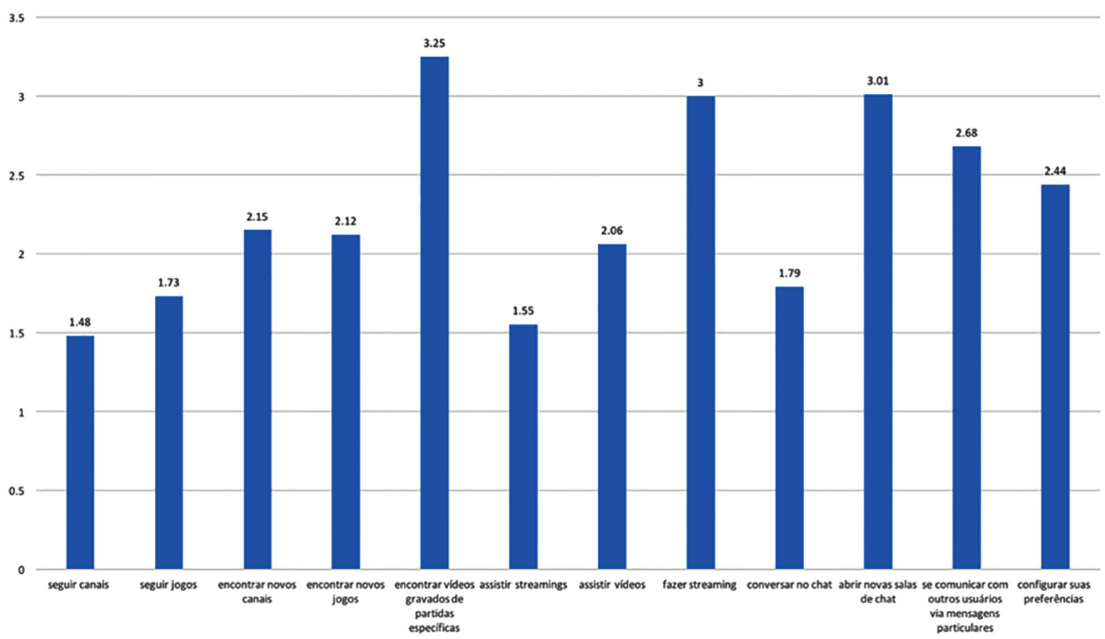

Desta vez o valor mais próximo de 1 indica maior facilidade para realizar a ação. Neste caso, assistir streaming e seguir canais são as ações mais fáceis de realizar, segundo os respondentes, enquanto encontrar vídeos gravados de partidas específicas é a atividade mais difícil.

Fonte: Os autores.

De acordo com esses dados, três atividades apresentam frequência maior que fazer streaming: assistir canais ao vivo, conversar no chat e procurar jogos para assistir, o que já adianta que a maior parte dos respondentes atuam apenas como espectadores.

Entre os usos considerados mais prazerosos e intuitivos, o Twitch foi comparado a outras plataformas (YouTube e Livestream, por exemplo). Os melhores resultados foram alcançados por assistir a campeonatos de e-sports e assistir a games sendo jogados ao vivo, com $76 \%$ das respostas, seguido de acompanhar jogadores profissionais (70\%), aprender novas técnicas/habilidades de jogos (59\%) e interagir com outros usuários (37\%). Essas preferências indicam que o Twitch está correto em sua opção por dar suporte à realização de campeonatos, pois esse é um fator importante para os interesses da audiência. Torna-se evidente, também, a relação direta entre assistir jogos ao vivo e o interesse na performance de jogadores profissionais nessas situações. 
Em relação aos usos considerados menos prazerosos ou intuitivos no Twitch, quando comparado a plataformas similares, ganham destaque assistir a vídeos gravados de partidas específicas (39\%), participar de comunidades (34\%), seguidas por interagir com outros usuários (27\%) e ter acesso a informações sobre games (27\%). Quando analisadas em conjunto, as respostas dessa questão e da anterior, nos levam ao entendimento de que o Twitch é uma boa plataforma de streaming de games, mas não é considerado tão bom em seu papel de site de rede social temático. O que fragiliza esse aspecto parece ser a baixa intuitividade das interfaces de interação entre usuários, já que 75\% dos respondentes afirmaram que utilizam o chat para conversarem, principalmente sobre o jogo que está sendo transmitido (45\%), mas também sobre assuntos não diretamente relacionados a jogos (humor e tecnologia, por exemplo) (34\%). A habilidade dos streamers é assunto de preferência de $22 \%$ das respostas.

Assistir a canais transmitindo jogos ao vivo é o uso declarado em 99\% das respostas dos usuários do Twitch, enquanto que assistir a vídeos gravados aparece como prática em apenas $13 \%$ delas, o que pode indicar o aspecto pouco intuitivo da plataforma nesse quesito.

Quando questionados sobre como classificariam os canais a que assistem, $49 \%$ das respostam indicam competitivos (e-sports), enquanto $40 \%$ sinalizam informação e entretenimento. Outros $7 \%$ classificam speedrunning ${ }^{12}$ e $5 \%$ walktrough $h^{13}$.

Apenas 35\% dos respondentes afirmaram realizar streaming de jogos. Os 65\% restantes figuram apenas como audiência. Entre os respondentes streamers, 78\% declararam que não possuem seus canais associados a um host, o que garantiria que os jogos fossem retransmitidos em outros canais, enquanto $22 \%$ responderam que os possuem.

Sobre os tipos de jogos que mais assistem, obteve-se os seguintes dados dos respondentes (FIG. 3): 
FIGURA 3. Gráfico com os jogos mais assistidos pelos respondentes ${ }^{14}$

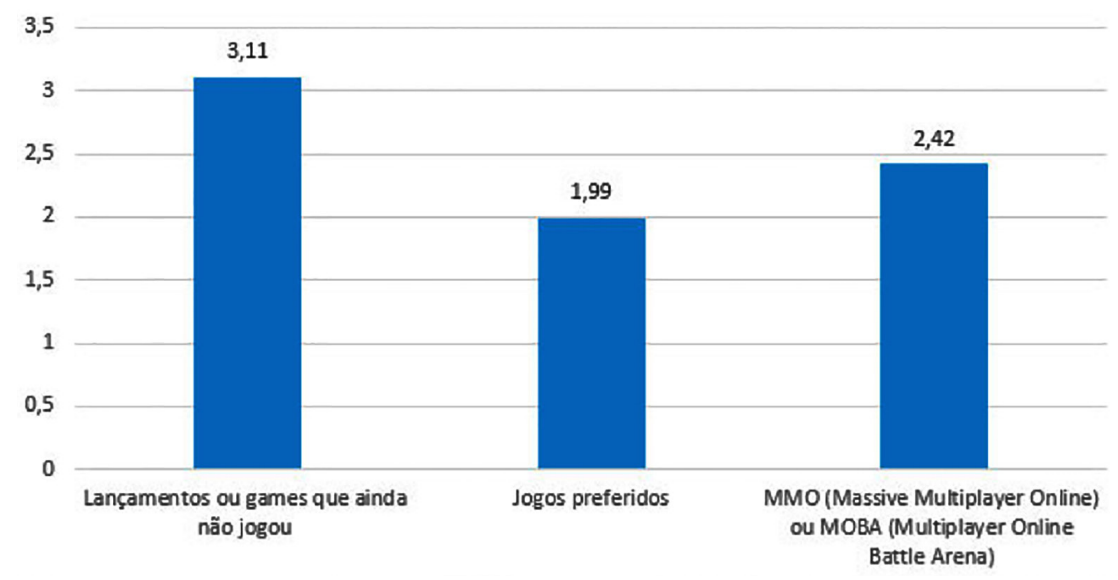

Fonte: Os autores.

Em questão idêntica a FIG. 3, porém desta vez os respondentes deveriam classificar quais os gêneros dos jogos singleplayer que mais assistem, obteve-se o FIG. 4:

FIGURA 4. Gráfico dos gêneros dos jogos singleplayer ${ }^{15}$

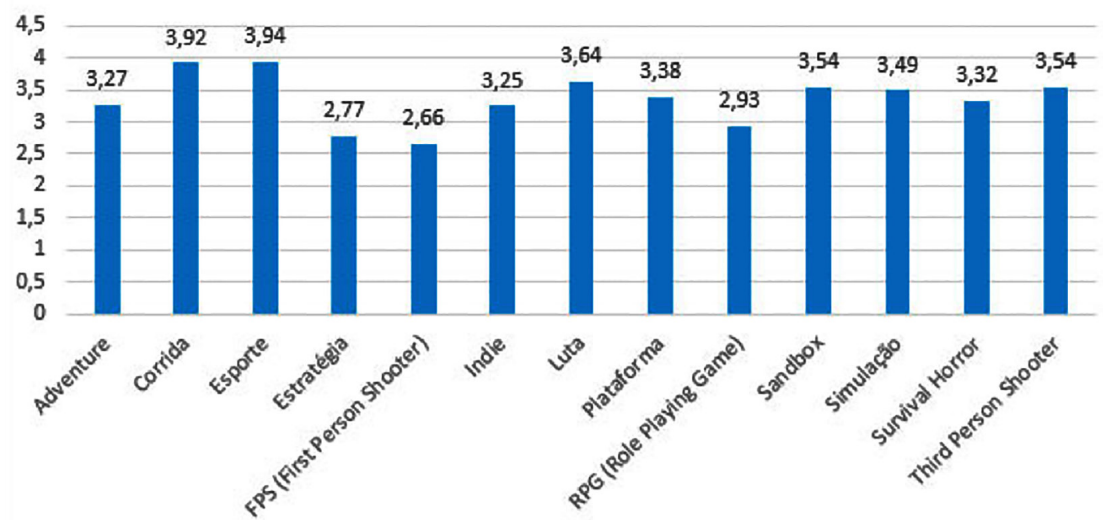

Fonte: Os autores.

$14 \mathrm{O}$ valor mais próximo de um identifica os tipos de jogos mais assistidos.

15 O valor mais próximo de um identifica os gêneros dos jogos singleplayer mais assistidos. 
Em seguida os respondentes classificaram o gênero dos jogos multiplayer que mais assistem.

FIGURA 5. Gráfico dos gêneros dos jogos multiplayer ${ }^{16}$

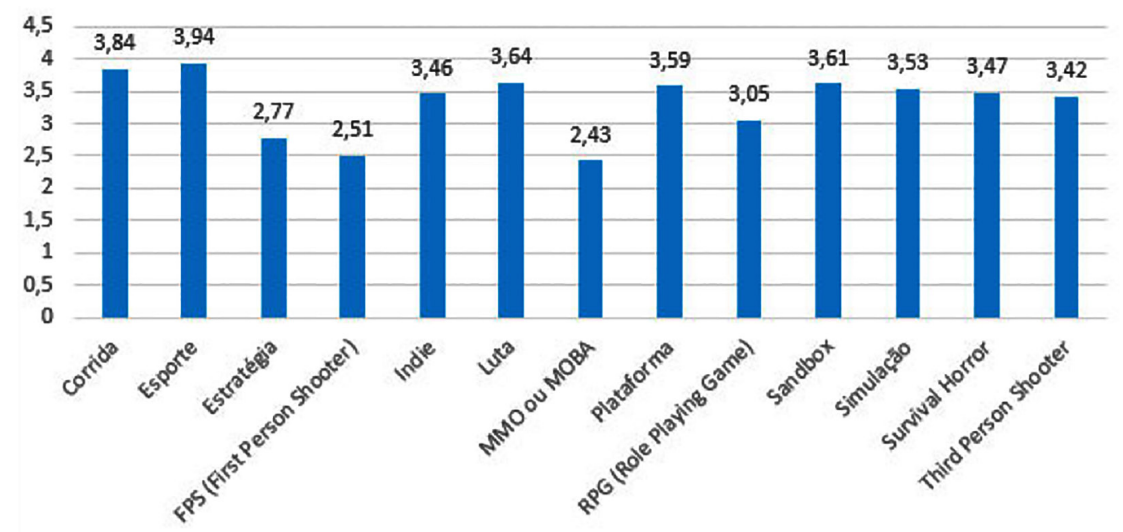

Fonte: Os autores.

$71 \%$ dos usuários seguem os seus jogos favoritos e $86 \%$, os canais que acessam. Em média, os respondentes seguem 27 canais. Quanto a inscreverem-se em seus canais favoritos, 54\% afirmam fazê-lo e 46\%, não. Para os usuários que se inscrevem nos canais, pagando U\$S 4,99 por mês, as principais vantagens incluem apoiar e aproximar-se do streamer, receber benefícios no chat e em promoções e poder participar de grupos e sessões multiplayer exclusivas para inscritos.

Carisma/simpatia e capacidade de entreter a audiência são as características mais apreciadas pelos respondentes nos streamers que mais gostam de assistir, constituindo a preferência de $53 \%$ de usuários. Habilidade no jogo (26\%) e habilidade em narrar o jogo (11\%) aparecem a seguir. Interessante notar que, quando se trata de transmitir jogos, na percepção dos usuários do Twitch, a preferência recai sobre a habilidade em transmitir quando comparado à habilidade de jogar.

16 O valor mais próximo de um identifica os gêneros dos jogos multiplayer mais assistidos. 
82\% dos respondentes acompanham seus streamers favoritos em sites de redes sociais, principalmente no Facebook (90\%), no YouTube (73\%) e no Twitter (60\%). Pode-se associar esse resultado ao aspecto pouco intuitivo do Twitch em relação à interação entre usuários e participação de comunidades, indicado anteriormente. No entanto, foi no próprio Twitch que 67\% dos respondentes afirmaram terem conhecido os seus streamers favoritos, enquanto que os $33 \%$ restantes já os conheciam de outras plataformas.

Na opinião de $66 \%$ dos respondentes, o streamer é o que há de mais importante nos canais do Twitch, seguido pelo game (33\%). Nessa questão, o chat aparece como opção de apenas $1 \%$ dos respondentes. No entanto, o chat é considerado muito importante no Twitch por $44 \%$ dos respondentes em questão que interroga diretamente sobre a relevância desse recurso. Para 34,5\% deles, o chat é razoavelmente importante e, para $21,5 \%$, não é importante, dados que podem indicar que muitos usuários apenas assistem aos jogos, sem interagir com os streamers.

Tanto a pesquisa documental do Twitch quanto a análise do questionário, permitem-nos constatar que, ao lado das funções de performance propostas por Schechner (2003), "marcar e mudar a identidade", "estimular uma comunidade", "ensinar, persuadir e convencer", pela primeira vez identifica-se, na pesquisa, a função "entreter”, que não havia aparecido nos trabalhos anteriores referidos na seção 2 deste texto. Essa função parece indicar uma verticalização na questão da performance no Twitch frente às análises precedentes, no sentido de apontar para a centralidade do papel do streamer na plataforma em relação ao dos espectadores. Mesmo em relação às funções de performance previstas por Schechner (2003) e identificadas em estudos anteriores, percebe-se que tanto streamers quanto viewers exercitam a percepção de si mesmos e a construção de suas identidades, sentem-se fazendo parte de uma comunidade e manifestam-se em diferentes sentidos, conforme o tipo de jogo e o canal em que este jogo é transmitido no Twitch, os streamers durante as transmissões ao vivo e nas gravações posteriormente disponibilizadas, 
assim como pelas interações possíveis entre os dois tipos de usuários no chat.

No entanto, as dificuldades apontadas em termos de interação entre os usuários na plataforma, e uma certa discrepância nas respostas obtidas com referência ao chat, reforçam a percepção da verticalização da performance do streamer no Twitch. Outro ponto que favorece esse entendimento é que a maioria dos respondentes atua apenas como espectadores (65\%), condição que não necessariamente exige o uso deste recurso.

A preferência por assistir jogos ao vivo reforça, no streamer, a importância do talento para entreter, enquanto joga, por meio de interação no chat por voz, e talvez, restrinja, ao menos durante as transmissões das partidas, a capacidade de interação desses jogadores com a maior parte da audiência.

Parece residir nesse aspecto a percepção de uma certa assimetria entre a performance atribuída pelos respondentes ao streamer, o que é inerente, ao mesmo tempo, à forma como o Twitch foi projetado e ao que é encorajado que seja realizado em termos de interações empreendidas neste espaço. Com isso, torna-se evidente que as oportunidades existentes, tanto de performar quanto de ter a sua performance avaliada no Twitch, favorecem a atuação do streamer neste contexto, sugerindo a emergência da função de performance "entreter" associada a este pelos respondentes e pela observação da plataforma.

\section{Considerações finais}

Levando em conta que consumo digital seja um aspecto constitutivo da prática de socialização online, e que implica a ação dos atores em espaços mediados, via manipulação dos recursos neles disponíveis, por meio de performances variadas, conclui-se que os aspectos sociotécnicos identificados no Twitch dependem da performance do streamer, sem o qual a plataforma não existiria. E se o broadcaster precisa de audiência, que, por sua vez, é mantida mais pela capacidade deste de entreter do que propriamente jogar, não surpreendem os esforços realizados pelos 
usuários para superar as limitações das interfaces. Para os espectadores, incluem-se, entre os benefícios de se inscrever nos canais, por pouco menos de cinco dólares por mês, proximidade e apoio ao streamer, via interação, o que aumenta as chances de performance da audiência no espaço.

Outro ponto que ressalta essa assimetria, é que, a performance dos streamers pode ser analisada tanto ao vivo quanto em vídeos gravados, enquanto que a dos espectadores, identificável em conversas por escrito, pode ser objeto de análise apenas no primeiro caso.

Em comparação com a literatura, constata-se que, enquanto em outros sites de redes sociais temáticos os usuários podem ter suas performances analisadas por texto escrito posteriormente às interações empreendidas, no Twitch as preferências dos respondentes apontam para acompanhamento de transmissões de jogos ao vivo, e as conversações entre usuários se perdem até mesmo nos vídeos gravados dessas partidas. Destaca-se assim a performance ao vivo do streamer em relação à sua audiência, de modo que as interações no chat incluem a participação do espectador na condução da própria transmissão, a partir do que o broadcaster considerar interessante no sentido de conferir-lhe popularidade.

Portanto, se os usuários têm papel ativo no estabelecimento de affordances em artefatos digitais, o Twitch demanda esforços especiais. Estes são diferentes se o usuário atuar como streamer ou viewer. No caso desta análise, essa condição afeta diretamente o uso dos recursos empregados nas interações, demandando esforços de superação das dificuldades do sistema em prol da performance do streamer, um jogador que, para ser popular no Twitch, deve encantar menos pela habilidade de jogar do que pela de se mostrar jogando. 


\section{Referências}

AMARO, M.; FREITAS, C. Pokémon, gotta catch them all: comunidade, jogo e memória. Sessões do Imaginário (PUCRS), Porto Alegre, v. 21, n. 35, p. 31-39, 2016. Disponível em: http://dx.doi.org/10.15448/1980-3710.2016.1.21249. Acesso em: 28 jun. 2017.

CASTIGLIONE, D.; VAN DETH, J.; WOLLEB, G. (Orgs.). The handbook of social capital. Nova York: Oxford University Press, 2008.

EHRENBERG, A. O culto da performance: da aventura empreendedora à depressão nervosa. Aparecida: Ideias\&Letras, 2010.

FALCÃO, T. Estruturas de agenciamento em mundos virtuais: mundos ficcionais como vetores para o comportamento social in-game. In: ENCONTRO DA COMPÓS, 19., 2010, Rio de Janeiro. Anais... Rio de Janeiro: PUC-RJ, 2010.

FRAGOSO, S. Meet the HUEHUEs. International Journal of Sociotechnology and Knowledge Development, Hershey, v. 6, n. 3, p. 26-44, 2014

FRAGOSO, S. 'HUEHUEHUE eu sou BR': spam, trollagem e griefing nos jogos online. Revista FAMECOS (PUCRS), Porto Alegre, v. 22, n. 3, p. 129-146, 2015. Disponível em: http://dx.doi.org/10.15448/1980-3729.2015.3.19302. Acesso em: 28 jun. 2017.

FRAGOSO, S.; REBS, R. R; BARTH, D. L. Interface affordances and social practices. In: AVI '12 International Working Conference on Advanced Visual Interfaces. Anais... p. 50-57. Ilha Capri, Itália, ACM, 2012. DOI: 10.1145/2254556.2254569.

FRAGOSO, S. Conectibilidade e geografia em sites de rede social: um olhar sobre as relações entre território e identidade a partir do Orkut. Galáxia (PUCSP), São Paulo, n. 16, p. 109-121, 2008. Disponível em: < https://revistas.pucsp.br/index.php/galaxia/ article/view/1921>. Acesso em: 28 jun. 2017.

FRAGOSO, S. Eu odeio quem odeia... considerações sobre o comportamento dos usuários brasileiros na tomada do Orkut. E-Compós, Brasília, n. 6, 2006. Disponível em: <http://compos.org.br/seer/index.php/e-compos/article/viewFile/89/89>. Acesso em: 28 jun. 2017.

GARRET, J. J. The elements of user experience: user-centered design for the web and beyond. New York: New Riders, 2011.

GARROCHO, L. F. M. de A. R.; JOSEPHSON, J. Z. de A. Rastros de um Dispositivo do Jogar: Agenciamento de Agrupamentos no Experimento Social Twitch Plays Pokémon. In: SIMPÓSIO NACIONAL DA ASSOCIAÇÃO BRASILEIRA DE PESQUISADORES EM CIBERCULTURA (ABCiber), 2014, São Paulo. Anais... São Paulo: ESPM, 2014.

GAVER, W. W. Affordances for interaction: the social is material for design. Ecological Psychology, 8(2), p. 111-129, 1996.

GIBSON, J. J. The Theory of affordances. In: SHAW, R. E; BRANSFORD, J. (Orgs.). Perceiving, acting, and knowing: toward an ecological psychology. Hillsdale: Lawrence Erlbaum Associates, 1977. p. 127-143.

HARTSON, H. R. Cognitive, physical, sensory, and functional affordances in interaction design. Behaviour E Information Technology, 22, 5, p. 315-338, 2003.

HUIZINGA, J. Homo ludens: o jogo como elemento da cultura. São Paulo: Perspectiva, 2010 . 
LEITE, G. F; TESSAROLO, F. M. A maior batalha de todos os tempos da semana passada. In: SIMPÓSIO NACIONAL DA ASSOCIAÇÃO BRASILEIRA DE PESQUiSADORES EM CIBERCULTURA (ABCIBER), 8., 2014, São Paulo. Anais... São Paulo: ESPM, 2014.

MONTARDO, S. P. Consumo Digital e Teoria de Prática: uma abordagem possível. In: Revista Famecos, v. 23, n. 2, pp. 1-15, 2016. Disponível em: http://revistaseletronicas. pucrs.br/ojs/index.php/revistafamecos/article/view/22203/14175. Acesso em: ago. 2016. MONTARDO, S. P; SILVA, T. D. T. Consumo digital, performance e livros: estudo comparativo entre os sites Skoob e Scribd. In: Revista Fronteiras (Online), v. 17, p. $23-$ 32, 2015a.Disponívelem: http://revistas.unisinos.br/index.php/fronteiras/article/view/ fem.2015.171.03/4556. Acesso em: 22 dez. 2015.

MONTARDO, S. P.; SILVA, T. D. T. Contém spoiler: performance e consumo no SRS temático Filmow. In: Alceu (PUCRJ), v. 15, p. 117-133, 2015b. Disponível em: http:// revistaalceu.com.pucrio.br/cgi/cgilua.exe/sys/start.htm?from $\% 5$ Finfo $\% 5$ Findex $=9 \&$ inf oid $=537 \&$ sid $=42$. Acesso em: 22 dez. 2015.

MONTARDO, S. P.; SILVA, T. D. T. Bazinga! Consumo e performance sobre The Big Bang Theory no Filmow. In: ENCONTRO NACIONAL DE HISTÓRIA DA MÍDIA, 10, 2015c, Porto Alegre. Anais... Porto Alegre: UFRGS, 2015c. Disponível em: http:// www.ufrgs.br/alcar/encontros-nacionais-1/encontros-nacionais/10o-encontro-2015/

historia-da-midia-digital/bazinga-consumo-e-performance-sobre-the-big-bang-theory-no-filmow/view. Acesso em: dez. 2015.

NEEDLEMAN, E. S. Twitch's viewers reach 100 million a month. In: The Wall Street Journal, New York, 29 jan. 2015. Disponível em: http://blogs.wsj.com/digits/2015/01/29/ twitchs-viewers-reach-100-million-a-month/. Acesso em: 28 jan. 2016.

NORMAN, D. O design do dia-a-dia. Rio de Janeiro: Editora Rocco, 2006.

PAZ, S. Twitch e o levantamento do estado da arte sobre o streaming ao vivo de games. In: ENCONTRO NACIONAL DE HISTÓRIA DA MÍDIA, 10. Anais... Porto Alegre. UFRGS, 2015.

RECUERO, R. A conversação em rede: comunicação mediada pelo computador e redes sociais na Internet. Porto Alegre: Sulina, 2014.

Redes sociais na internet. Porto Alegre: Sulina, 2009.

SCHECHNER, R. O que é performance. O Percevejo, 12, p. 1-10, 2003.

SOMMERSETH, H. Gamic realism: player, perception and action in video game play. In: DIGITAL GAMES RESEARCH ASSOCIATION CONFERENCE, Tóquio, 2007. Anais... Tóquio, 2007. Disponível em: http://citeseerx.ist.psu.edu/viewdoc/download?do $\mathrm{i}=10.1 .1 .190 .3832 \& \mathrm{rep}=$ repl\&type=pdf. Acesso em: 10 fev. 2016.

TWITCH. About. About Twitch. Disponível em: http://www.twitch.tv/p/about. Acesso em: 30 jan. 2016.

WARDE, A. Consumption and theories of practice. In: Journal of Consumer Culture, v. 5, n 2, p. 131-153, 2005. Disponível em: <http://www.espm.br/Pesquisadores_versaol/ CAEPM/Documents/Consumption\%20and\%20Theories\%20of\%2 0Practice.pdf>. Acesso em: 04 fev. 2013. 
Sandra Montardo - Professora do PPG em Processos e Manifestações Culturais, PPG em Diversidade Cultural e Inclusão Social, Mestrado em Indústria Criativa e Curso de Comunicação da Universidade Feevale.

Suely Fragoso - Professora dos PPGs em Comunicação e Informação e em Design da UFRGS e Pesquisadora do CNPq.

Mariana Amaro - Doutoranda no Programa de Pós-Graduação em Comunicação e Informação pela UFRGS.

Samyr Paz - Mestre em Processos e Manifestações Culturais pela Universidade Feevale.

Data de submisão: 30/11/2016

Data de aceite: 24/05/2017 